\title{
Use of Process Modeling in Product Development Integration within Manufacturing Environment
}

\author{
SYED M Hasan ${ }^{1, a}$ and SATYA Shah ${ }^{2, b}$ \\ ${ }^{1}$ Centre of Innovative Product Development and Manufacturing \\ Faculty of Engineering and Science, University of Greenwich \\ Medway Campus, Chatham, Kent - ME4 4TB, United Kingdom \\ ${ }^{2}$ Centre of Innovative Product Development and Manufacturing \\ Faculty of Engineering and Science, University of Greenwich \\ Medway Campus, Chatham, Kent - ME4 4TB, United Kingdom \\ a s.m.hasan@gre.ac.uk, ${ }^{\mathrm{b}}$ s.shah@gre.ac.uk
}

\begin{abstract}
Keywords: New Product Development (NPD), Supply Chain Management (SCM), Co-ordination, Modelling Tools, Modelling Languages, Integrated Framework.
\end{abstract}

\begin{abstract}
The impact of supply chain on new product development (NPD) and product introduction is particularly important in a time when (i) there are pressures for growing product proliferation in order to meet varied demands and constraints, (ii) the research and development pipeline is a key focus in companies, and (iii) technology life cycles have shortened so much that obsolete inventories and time to market are crucial for companies' margin performance. This research focuses on the early stages of the collaborative product development process in the extended enterprise and shows it is a contribution to the business world. The output of the research includes the functional requirements of a framework and a developed prototype methodology with tools and technologies that are tested with case studies in the industrial environment. The study also focuses on using modern modeling tools to represent the product development processes of an Original Equipment Manufacturer (OEM) and its suppliers.
\end{abstract}

\section{Introduction}

As whole, the manufacturing firms, in order to be more competitive in market, must continuously update their product offers in order to satisfy customers' requirements better. To deliver the products at the targeted cost, time, and quality, the supply chain must be aligned with product development decisions. This will allow the manufacturing firm to overcome problems such as (partially) failed product launches due to the lack of product availability because of insufficient capacities [1]. The problem lies is here is that the supply chain covers a wide area of business cycle and on the other hand the new product development relates only to manufacturing. So linking these two attributes of the business is not an easy task to accomplish. The other issue which has been raised through literature studies which shows the lack of evidence for detailed framework existing that demonstrates the linkage between SCM and NPD. In almost every business sector they need a tool which shows the impact of linking [2].

\section{Literature Review}

Process. To understand this research, we need to understand clearly about the process first, which is the basic of any business firm. Different tasks that create a value added product is called a business process. The common goals for these different processes are [3]

(1) Satisfied customer; (2) Investment return and last but not the least; (3) Profit in market share According to Kenneth preiss, the primary variable in the flow of process is to look at the flows in and out of a single enterprise [4]. Fig. 1 shows the standard model of a process in general. 


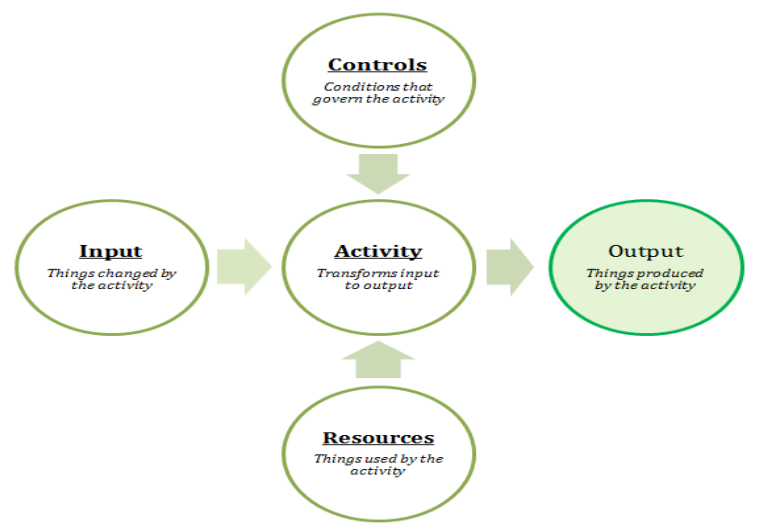

Fig. 1 The description of Process based on Kenneth Preiss Model

Process Modeling Tools. A modeling tool can be graphical or textual.

- Graphical modeling tools use a diagram technique with named symbols that represent concepts and lines that connect the symbols and represent relationships and various other graphical notations to represent constraints.

- Textual modeling tools typically use standardized keywords accompanied by parameters to make computer-interpretable expressions.

The focus in this research is on graphical type as textual modeling languages are intended for computer science field.

Graphical Type. Some of the eexample of graphical modeling languages in the field of computer science, project management and systems engineering:

- Business Process Modeling Notation (BPMN, and the XML form BPML) is an example of a Process Modeling language.

- EXPRESS and EXPRESS-G (ISO 10303-11) is an international standard general-purpose data modeling language.

- Extended Enterprise Modeling Language (EEML) is commonly used for business process modeling across a number of layers.

- Flowchart is a schematic representation of an algorithm or a stepwise process,

- Fundamental Modeling Concepts (FMC) modeling language for software-intensive systems.

- $I D E F$ is a family of modeling languages which is described later

- Object Role Modeling (ORM) in the field of software engineering is a method for conceptual modeling, and can be used as a tool for information and rules analysis.

- Petri nets use variations on exactly one diagramming technique and topology, namely the bipartite graph. The simplicity of its basic user interface easily enabled extensive tool support over the years, particularly in the areas of model checking, graphically-oriented simulation, and software verification.

- South beach Notation is a visual modeling language used to describe situations in terms of agents that are considered useful or harmful from the modeler's perspective. The notation shows how the agents interact with each other and whether this interaction improves or worsens the situation.

- Specification and Description Language (SDL) is a specification language targeted at the unambiguous specification and description of the behavior of reactive and distributed systems.

- SysML is a Domain-Specific Modeling language for systems engineering that is defined as a UML profile.

- Unified Modeling Language (UML) is a general-purpose modeling language that is an industry standard for specifying software-intensive systems.

- Service-Oriented Modeling Framework (SOMF) is a holistic language for designing enterprise and application level architecture models in the space of enterprise architecture, virtualization, service-oriented architecture (SOA), cloud computing, and more.

Some of the modeling languages have been discussed below in detail: 
- Unified Modeling language. UML is a standardized general-purpose modeling language which includes a set of graphic notation techniques to create visual models of object-oriented software-intensive systems. UML is used to specify, visualize, modify, construct and document the artifacts of an object-oriented software-intensive system under development. UML offers a standard way to visualize a system's architectural blueprints, including elements such as: activities, actors, business processes, database schemas, logical components, programming language statements and reusable software components

- IDEF. An abbreviation of Integration Definition refers to a family of modeling languages in the field of systems and software engineering. They cover a wide range of uses, from functional modeling to data, simulation, object-oriented analysis/design and knowledge acquisition. The IDEF Functional Modeling method is designed to model the decisions, actions, and activities of an organization or system.

- Business Process Model and Notation. Business Process Model and Notation (BPMN) is a standard for business process modeling that provides a graphical notation for specifying business processes in a Business Process Diagram (BPD), based on a flowcharting technique very similar to activity diagrams from Unified Modeling Language (UML). The objective of BPMN is to support business process management, for both technical users and business users, by providing a notation that is intuitive to business users, yet able to represent complex process semantics. The BPMN specification also provides a mapping between the graphics of the notation and the underlying constructs of execution languages, particularly Business Process Execution Language (BPEL). The primary goal of BPMN is to provide a standard notation readily understandable by all business stakeholders. These include the business analysts who create and refine the processes, the technical developers responsible for implementing them, and the business managers who monitor and manage them. Consequently, BPMN serves as a common language, bridging the communication gap that frequently occurs between business process design and implementation.

- Flow Chart. A flowchart is a type of diagram that represents an algorithm or process, showing the steps as boxes of various kinds, and their order by connecting them with arrows. This diagrammatic representation can give a step-by-step solution to a given problem. Process operations are represented in these boxes, and arrows connecting them represent flow of control. Flowcharts are used in analyzing, designing, documenting or managing a process or program in various fields. Flowcharts are used in designing and documenting complex processes or programs. Like other types of diagrams, they help visualize what is going on and thereby help the viewer to understand a process, and perhaps also find flaws, bottlenecks, and other less-obvious features within it. There are many different types of flowcharts, and each type has its own repertoire of boxes and notational conventions.

\section{Proposed Framework}

Based on the simple supply chain concept of supply chain in which product starts from customer requirement and goes to the final stage where it has been delivered to customer in a market.

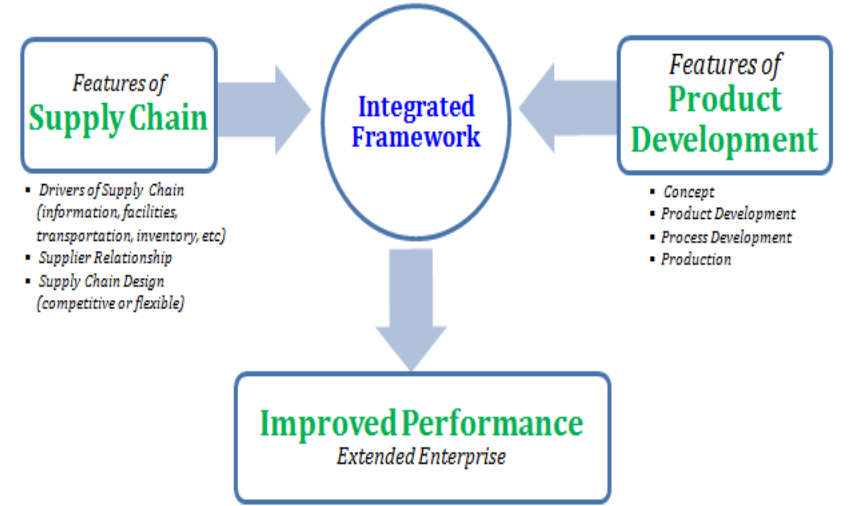

Fig. 2: Idea of framework to integrate features of supply chain with product development [6] 
While keeping in mind the Kenneth Preiss model, the basic supply chain activities can be transformed in the following way which has worked as the proposed framework/model in Fig. 3.

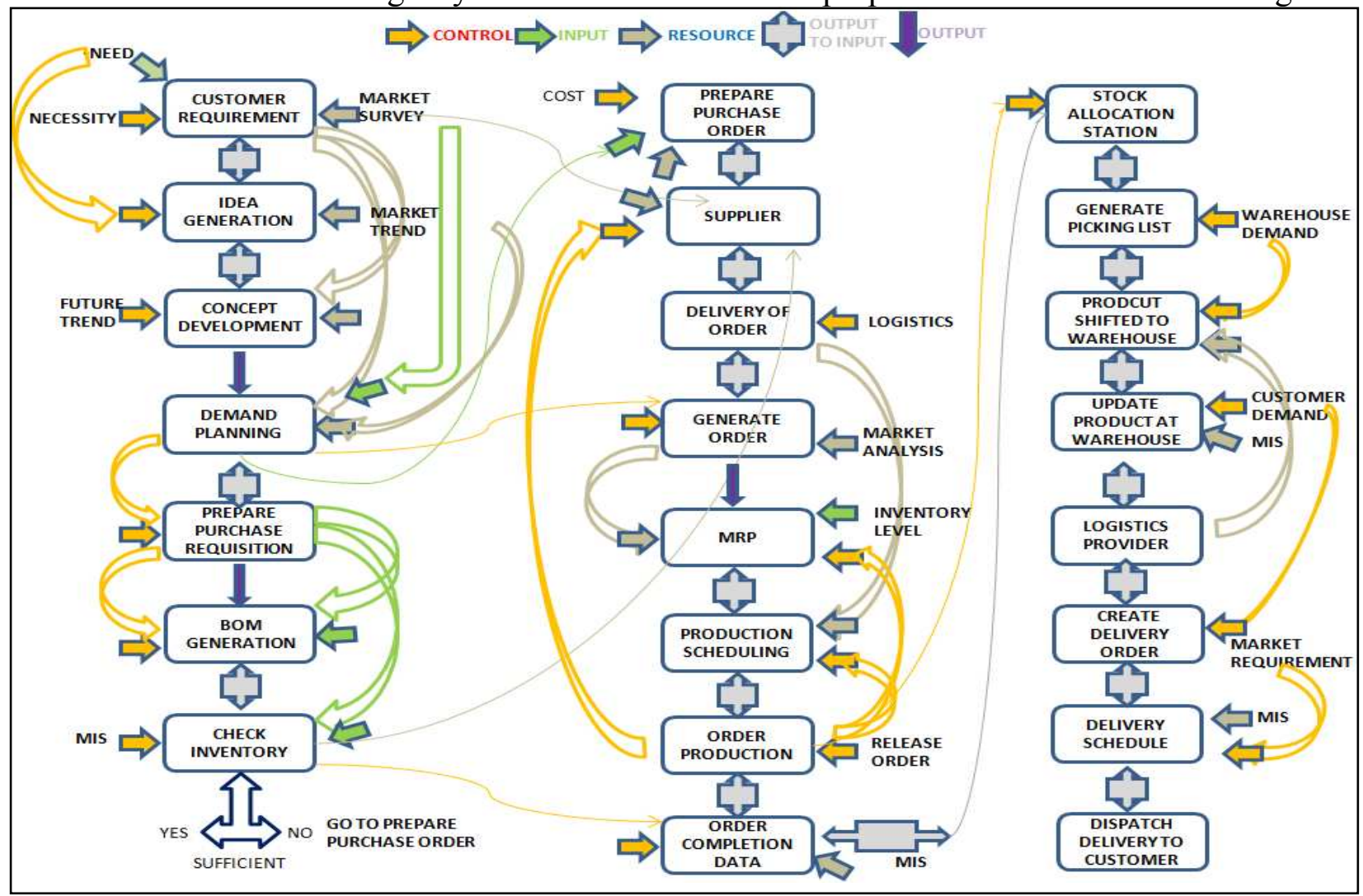

Fig. 3: Basic concept of supply chain processes

All the factors which are involved in defining the process have been reported in this Fig. 3 and have been linked with each other too. This conceptual framework shows the multiple integrated points and different possible decision making points to analyze before the product touched the approval stage for customer. In later stage, this conceptual framework has been transformed in functional processes of basic supply chain Fig. 4.

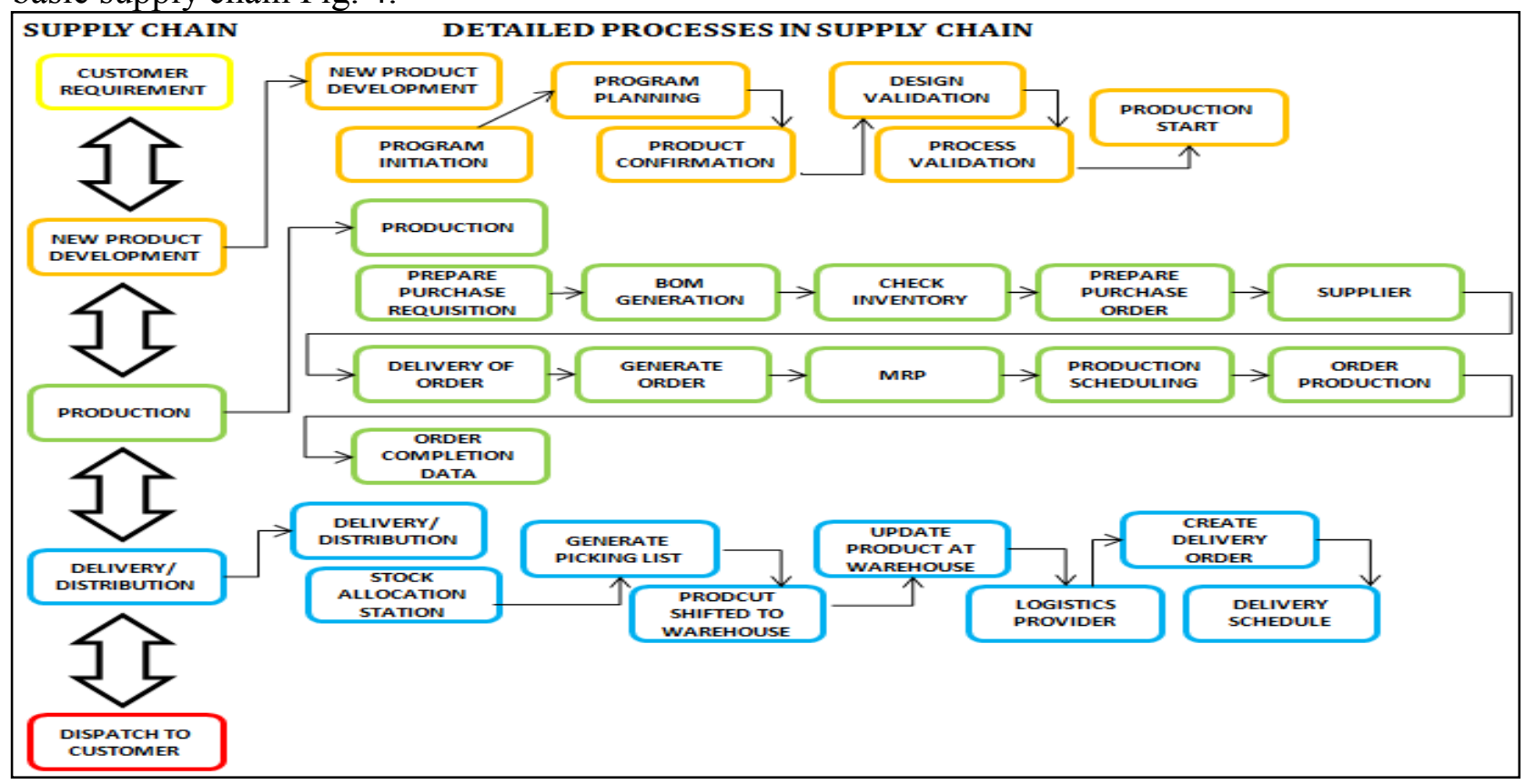

Fig. 4: The Supply Chain Processes with Detailed Sub-processes [7]. 


\section{Conclusion}

Based on discussed modeling tools within the supply chain context, the modeling language has been selected at the current stage of research. This modeling tool has been used to define the industrial investigation results which have been performed in later stage of the research in a form of case analysis in the automotive enterprise. This current conceptual framework helped the study to understand the different points of integration and their effects in NPD-SCM scenarios. While transformed framework helped us in understanding of the functional requirement of the supply chain which helps in identifying the key characteristics for business simulation to analyses the "AS-IS" situation. Further studies on the basis of this current state map, the possible integration points can easily be analyzed and then lately be categorized to form a generalized framework for the whole enterprise and not just the new product development (NPD).

\section{References}

[1] R. Van Hoek, and P. Chapman, How to move supply chain beyond cleaning up after new product development, An International Journal of Supply Chain Management, 12, No. 4 (2007), 239-244.

[2] M. Pero, N. Abdelkafi, A. Sianesi, T. Blecker, A framework for the alignment of new product development and supply chains, International Journal of Supply Chain Management, 15, No. 2 (2011), 127-130.

[3] H. B. Marri, R. J. Grieve, A. Gunasekaran, B. Kobu, Government-industry-university collaboration on the successful implementation of CIM in SMEs: An empirical analysis, Journal of Logistics Information Management, 15, No. 2 (2002).

[4] P. Kenneth, Modeling of knowledge flows and their impact, Journal of Knowledge Management, 3, No. 1 (1999) 36-46.

[5] H. Park and M. R.Cutkosky, Framework for modeling dependencies in collaborative engineering processes, Research in Engineering Design, 11, No. 1 (1999). 84-102.

[6] S. M. Hasan, S. Shah and J. Gao, A collaboration framework for product development in extended enterprise, Proceedings of 10th international conference on manufacturing research Advances in Manufacturing Technology, XXVI, 2 (2012).

[7] S. M. Hasan, S. Shah and J. Gao, A collaboration framework to support decision making in new product development with the supply chain, Submitted in International Conference on Manufacturing Research, 19-20 September 2013, Cranfield University, UK. 
